\title{
Thermal and Bioenergetics Modeling For Balancing Energy and Environment
}

\author{
Gary E. Hauser, M. ASCE \\ John Stark \\ George Robbins ${ }^{3}$, M ASCE \\ Bethel Herrold
}

Abstract

Dynamic thermal and bioenergetics models were applied to help define issues, identify alternatives, and quantify effects of various reservoir releases improvement options for Bull Shoals and Norfork Dams in northern Arkansas.

\section{Introduction}

Bull Shoals and Norfork Dams in northern Arkansas produce a combined $420 \mathrm{MW}$ hydropower capacity plus tailwater trout fisheries (brown, cutthroat, and rainbow). The dams are owned and operated by the U.S. Army Corps of Engineers, Little Rock District (LRD-USACE); the hydropower is marketed by Southwestern Power Administration (SWPA); and the fisheries are managed by Arkansas Game and Fish Commission (AGFC). These organizations are participating in efforts to identify cost-effective reservoir release strategies that provide for a sustainable balance of energy and environment in the region. This paper describes tailwater modeling conducted for this purpose. Models were calibrated and used to quantify potential effectiveness of a range of operations and technologies for improving physical habitat (depths, velocities, wetted areas), boat navigability, temperature, dissolved oxygen (DO), and fish growth response. This paper includes background on the modeling system; an overview of relevant agency perspectives; and selected examples of simulated responses to dam operations.

\footnotetext{
${ }^{1}$ Sr. Technical Specialist, Tennessee Valley Authority, 129 Pine Road, Norris, TN 37828

${ }^{2}$ State Trout Biologist, Arkansas Game and Fish Commission, Mountain Home, AR

${ }^{3}$ Hydraulic Engineer, Southwestern Power Administration, Tulsa, OK

${ }^{4}$ Hydraulic Engineer, Southwestern Power Administration, Tulsa, OK
} 
Modeling objectives were 1) to characterize river hydraulics and water quality over a range of operations; 2) to identify minimum flow strategies that could achieve thermal objectives for the fishery with minimal hydropower impact; and 3) to quantify fish growth responses to alternative release improvement measures. This modeling was exploratory, limited to the downstream effects of dam release quantity and quality. Issues for upstream reservoirs were not included in this scope (e.g., impacts on seasonal cold water availability, pool levels, storage allocations, hydropower, and facilities).

\section{Study Reach}

The geographic focus of this modeling was confined to the tailwater reaches from the dams to the confluence of Bull Shoals and Norfork tailwaters (Figure 1). The Bull Shoals tailwater model covered 47 miles from the dam at White River Mile (WRM) 418.41 to WRM 370.9, the lower boundary of which is just below the confluence with the Norfork tailwater at WRM 376.4. The Norfork tailwater model covered 4.6 miles from the dam at North Fork River Mile (NFRM) 4.8 to just above the mouth at NFRM 0.19. The Buffalo River confluence is at WRM 387.7.

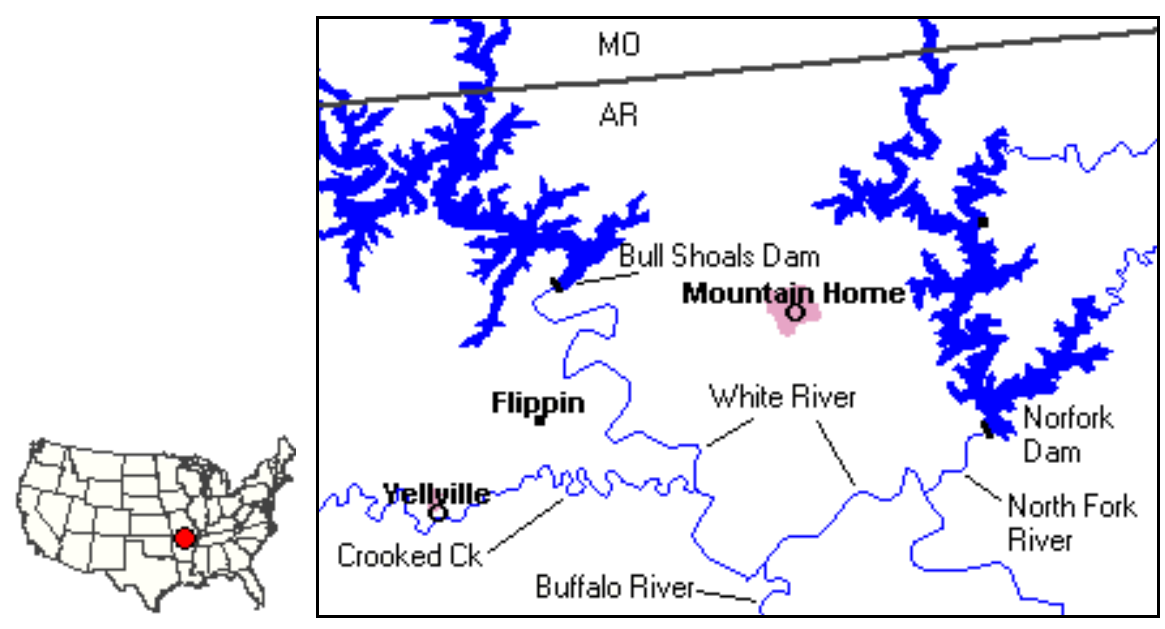

Figure 1. Map of Bull Shoals and Norfork Tailwaters

AGFC Perspective

The Arkansas Game and Fish Commission is responsible for managing Arkansas' tailwater fisheries resources. Specific management of the White River tailwaters downstream of Beaver, Bull Shoals, Norfork, and Greers Ferry Dams is assigned to the Statewide Trout Program.

Historically each of these tailwater stretches contained nationally known warm water fisheries dominated by smallmouth bass. In each case, cold water releases from the newly constructed dams radically changed environmental conditions and resulted in the loss of the native fisheries. Trout were stocked in the new cold water stretches in an attempt to provide fishing opportunities. As 
with the previous fisheries, trout fishing contributes greatly to the economy of Northern Arkansas. The tailwater fisheries below Norfork and Bull Shoals Dams generate an estimated \$80-100 million annually in local recreation benefits before recent aeration improvements and with current minimum flows.

However, historical challenges to the maintenance of these fisheries continue to this day and are particularly acute in Bull Shoals and Norfork tailwaters. During non-generation periods, minimal releases result in dewatering of forage producing riffle areas, greatly reduce adult trout habitat, and cause water temperatures to rise to critical levels. The current modeling study was initiated by AGFC to determine sufficient minimum flows for better maintenance of the previously described critical environmental factors.

\section{SWPA Perspective}

SWPA is an agency within the United States Department of Energy and is responsible for marketing the power and energy generated at 24 U.S. Army Corps of Engineers (Corps) hydroelectric power projects located in Arkansas, Missouri, Oklahoma, and Texas. SWPA, established in 1944, is mandated by Federal law to market the power and energy at cost-based rates consistent with sound business principles. Approximately six million end-users in a six-state area benefit from the electricity marketed by SWPA. SWPA is responsible to repay to the U.S. Treasury all costs assigned to hydropower at the projects. Those costs include the initial investment in the dam; interest on that investment; and operation, maintenance, and replacement costs for the Corps and SWPA.

SWPA recognizes the increasing demands placed on the limited water resource that is essential for the production of power and energy in its hydropower system. It has adopted a practice of strategic accommodation for dealing with the competing water users. The strategy for protection of the hydropower resource is to work cooperatively with other water resource interests to meet their needs to the extent possible while avoiding or minimizing adverse impacts on hydropower production. Some of the adverse impacts to hydropower production that can result from accommodating other water resource uses, such as increased downstream releases, include: 1) limiting operational flexibility, 2) reducing energy production, 3 ) reducing marketable capacity, and 4) increasing costs and electrical rates. The challenge is to understand the desires of the other water resource users to the extent that a solution can be developed that would be beneficial to others without adversely affecting SWPA's ability to market the electricity and meet its legal and financial obligations.

\section{TVA River Modeling System}

TVA's one-dimensional river modeling system includes hydrodynamic (ADYN), water quality (RQUAL), physical habitat (RHAB), and bioenergetics (FISH) modules, as described by Hauser (1991) and Shiao (1993). The hydrodynamics module simulates dynamic discharge, water surface, wetted area, 
velocity, depth and related hydraulic variables throughout the reach. The water quality module uses modeled hydrodynamics to simulate dynamic temperature, DO, and carbonaceous and nitrogenous oxygen demands. The bioenergetics module uses dynamic temperature, DO, and food availability to predict growth of an individual fish of a certain species. The bioenergetics module includes food consumption, assimilation, respiration, and growth, but it does not include effects of competition, predation, or mobility. Models were calibrated with streamgage records, travel times from dye studies, local meteorology, temperatures, and DO data from dam releases and multiple river stations.

\section{Tailwater Hydraulic Characteristics}

AGFC wants minimum flows below the dams to enhance wetted area (physical habitat) and to improve boat navigability between turbine operations. Changes in water depth and wetted area were modeled for a range of dam discharges. Figure 2 shows longitudinal depths for various Bull Shoals discharges, and Figure 3 shows wetted area versus discharge for key shoals. Modeled depth and wetted area increased significantly for initial increments of minimum flow above existing levels. For example, wetted area increases in certain shoals areas were $28 \%$ and $13 \%$ per $100 \mathrm{cfs}$ in Bull Shoals and Norfork tailwaters, respectively, for the first increments of increased minimum discharge. These rates of increase diminished at higher dam releases as flow began to fill the channel from bank to bank at all locations. Associated power costs are likely to increase exponentially with increasing minimum release. These patterns suggest an optimal minimum release that would provide greatest environmental benefit (i.e., most wetted area or depth increase) per dollar cost.

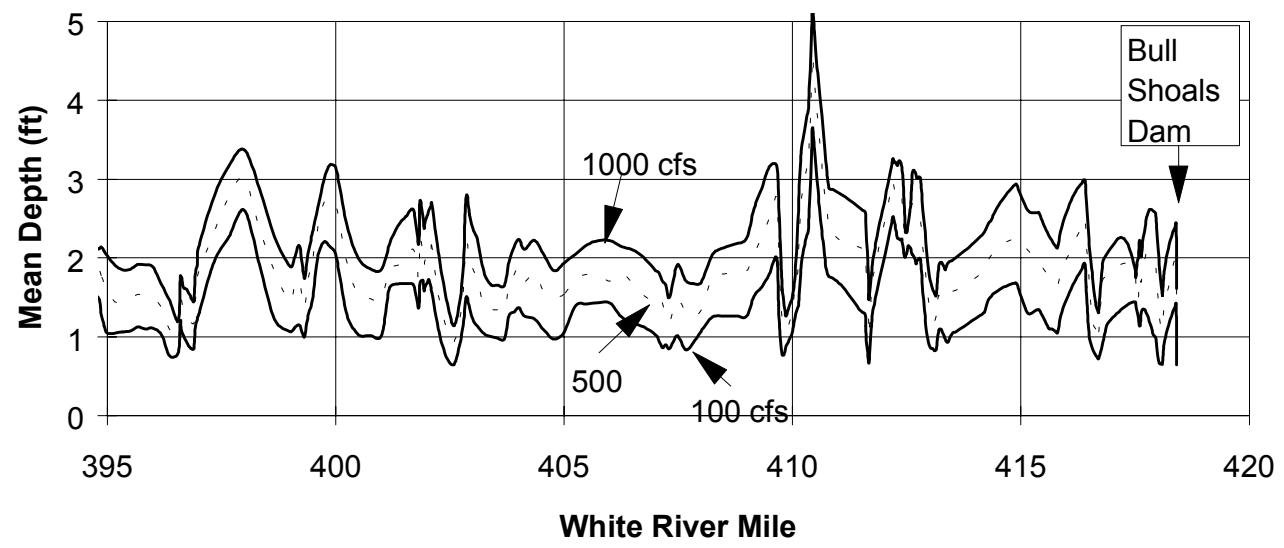

Figure 2. Effects of Discharge on Water Depths

The geometry of Bull Shoals tailwater provides good damping of shortduration pulse releases from the dam within a few miles of the dam, and this is important for any "continuous" minimum flow that might be established. Depth fluctuations caused by generating for 0.5 hour with one turbine every four hours dampen to about $0.3 \mathrm{ft}$ within four miles of Bull Shoals Dam. Turbine pulsing is 


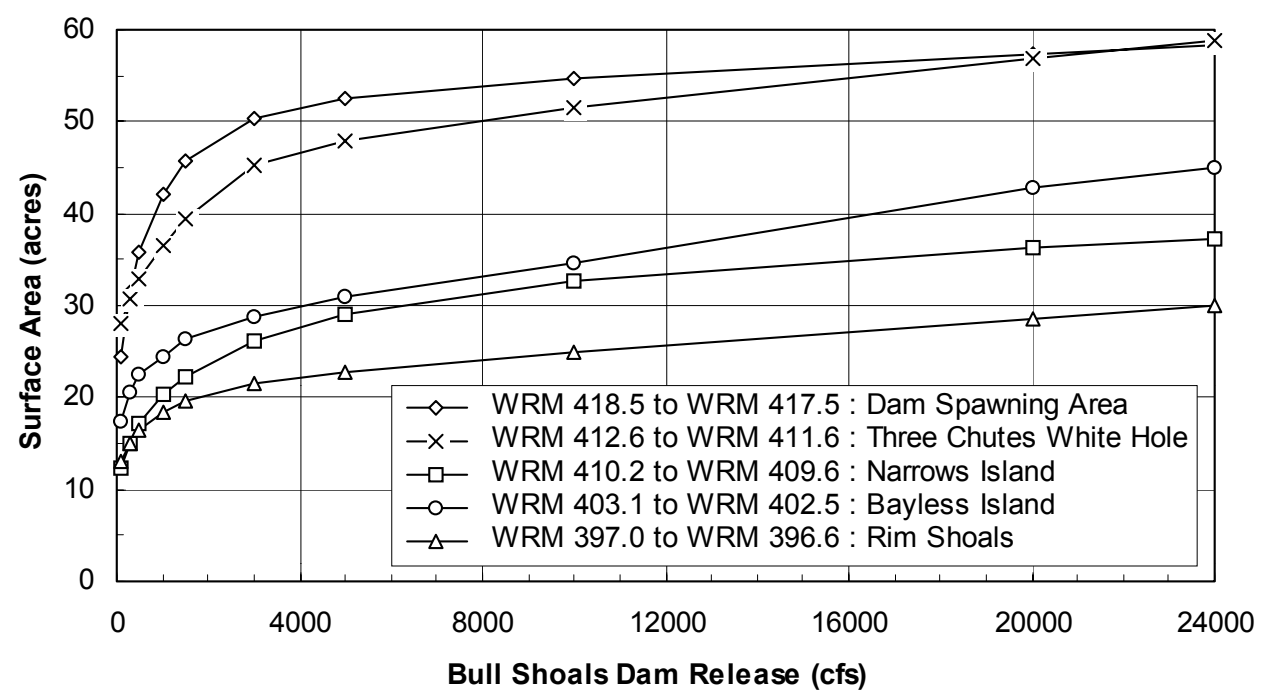

Figure 3. Effects of Discharge on Wetted Area at Selected Shoals Area

much more economical for providing "continuous" minimum flow than 1) sluicing, which bypasses the turbines altogether, or 2) small unit generation, which requires capital modifications and which would reduce efficiency, energy value, and marketable capacity relative to the large units. In one example below a TVA dam, continuous minimum flows of twice the original target were achievable with turbine pulsing, at a quarter of the cost of the best continuous option (sluicing), which just met the original target.

Travel time for a parcel of water from Bull Shoals to reach the North Fork River confluence varies from 1 to 3 days under a variety of modeled summer operations (Figure 4). This is significant for temperature control below the Buffalo River confluence, because it means yesterday's release volume from Bull Shoals has greater effect on today's water temperature than today's release. Under leakage conditions, travel time would increase to between 6 and 8 days. Below Norfork, travel times ranged from 2 hours at full turbine flow to 18 hours at leakage flows.

\section{Dam Releases and Temperature}

Episodes of excessive warming for trout now occur throughout the tailwater under certain operations, but a primary focus is the reach between the Buffalo River confluence with the North Fork confluence. Excessive temperatures occur in this lower reach due to the distance from Bull Shoals Dam and the relatively warm Buffalo River inflow. AGFC wants a minimum release strategy that supports thermal objectives for the fishery, including ceilings of $21.7^{\circ} \mathrm{C}\left(71^{\circ} \mathrm{F}\right)$ above the confluence with Buffalo River and $22.8 \mathrm{C}\left(73^{\circ} \mathrm{F}\right)$ below. Current minimum flow policy at Bull Shoals and Norfork calls for a combined 3-day volume of 6000 cfs-days and daily minima (less than $750 \mathrm{cfs}$ ) depending on air temperature.

Figure 4. Effects of Dam Operations on Travel Time 

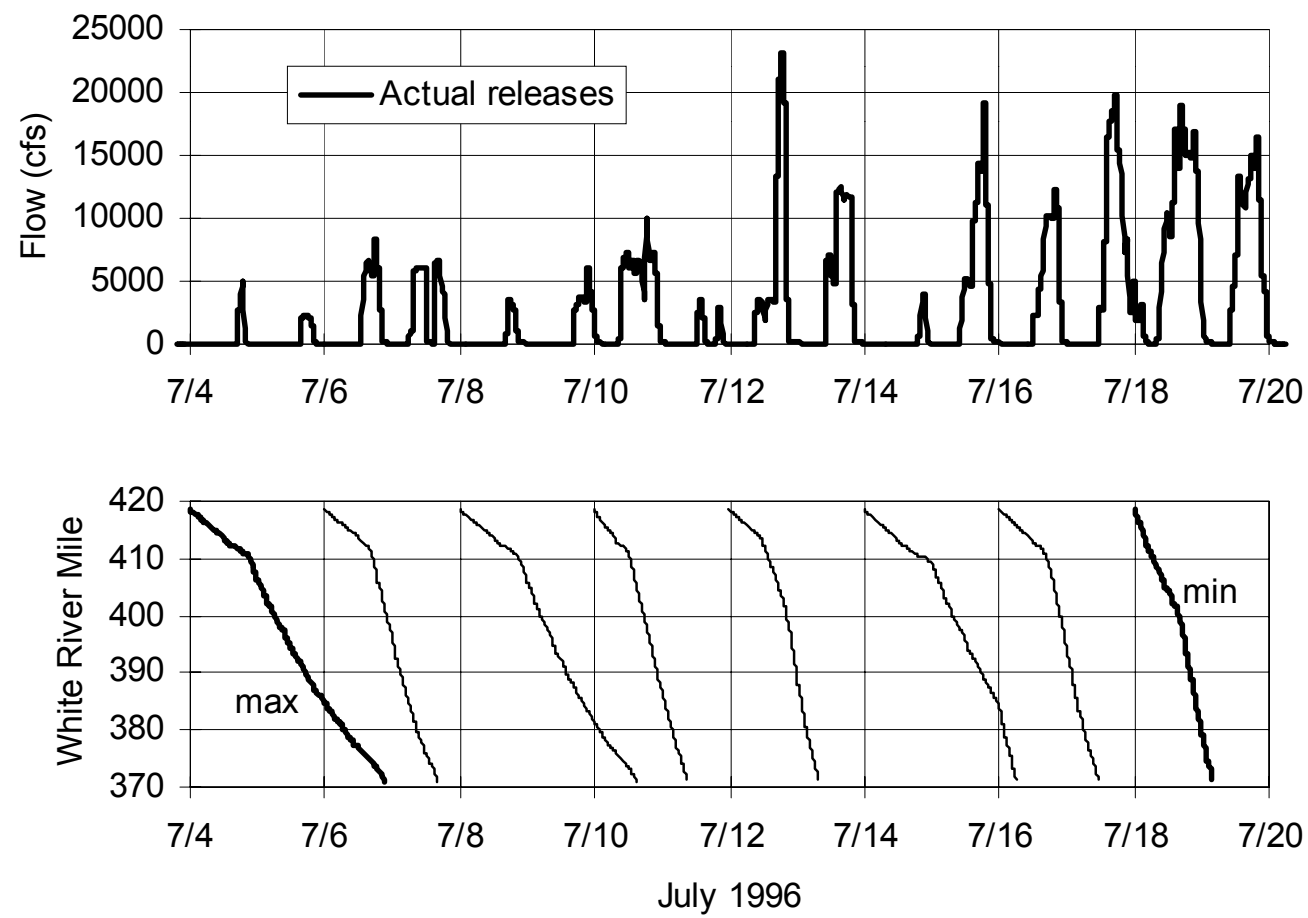

If neither dam needs to generate, the 3-day volume is split $80 \%$ from Bull Shoals and $20 \%$ from Norfork.

Model results of actual operation versus hypothetical weekend shutoff (Figure 5) showed that current minimum flow policy already provides a significantly improved thermal condition (see July 7-8 and July 14-15 in Figure 5) relative to a completely flexible hydropower operation with complete shutoff during low demand periods. However, modeling revealed that AGFC thermal objectives cannot consistently be met with the current 3-day combined volume strategy because it allows near shutoff at Bull Shoals for two days if Norfork is carrying the generation.

Simulations were made to determine if AGFC thermal objectives could be met, under periods of extended shutoff, if Bull Shoals were to provide $80 \%$ of the 3-day combined volume consistently (not just when generation from neither hydroplant is needed). Modeling results indicated that this volume would be sufficient to meet AGFC thermal objectives if the flow were properly distributed over the three days.

Since modeling showed that a 2-day shutoff at Bull Shoals would not meet AGFC thermal objectives, it was suggested that releases be consistently provided over shorter averaging periods than three days, such as a 1-day volume of $1600 \mathrm{cfs}-$ days or perhaps a 2-day volume of $3200 \mathrm{dsf}$. Use of a 2-day volume of $3200 \mathrm{cfs}-$ days rather than 1-day 1600 cfs-days could meet AGFC limits while allowing near shutoff on the second day. The second day's required minimum volume would likely depend on the size and hourly distribution of the previous 

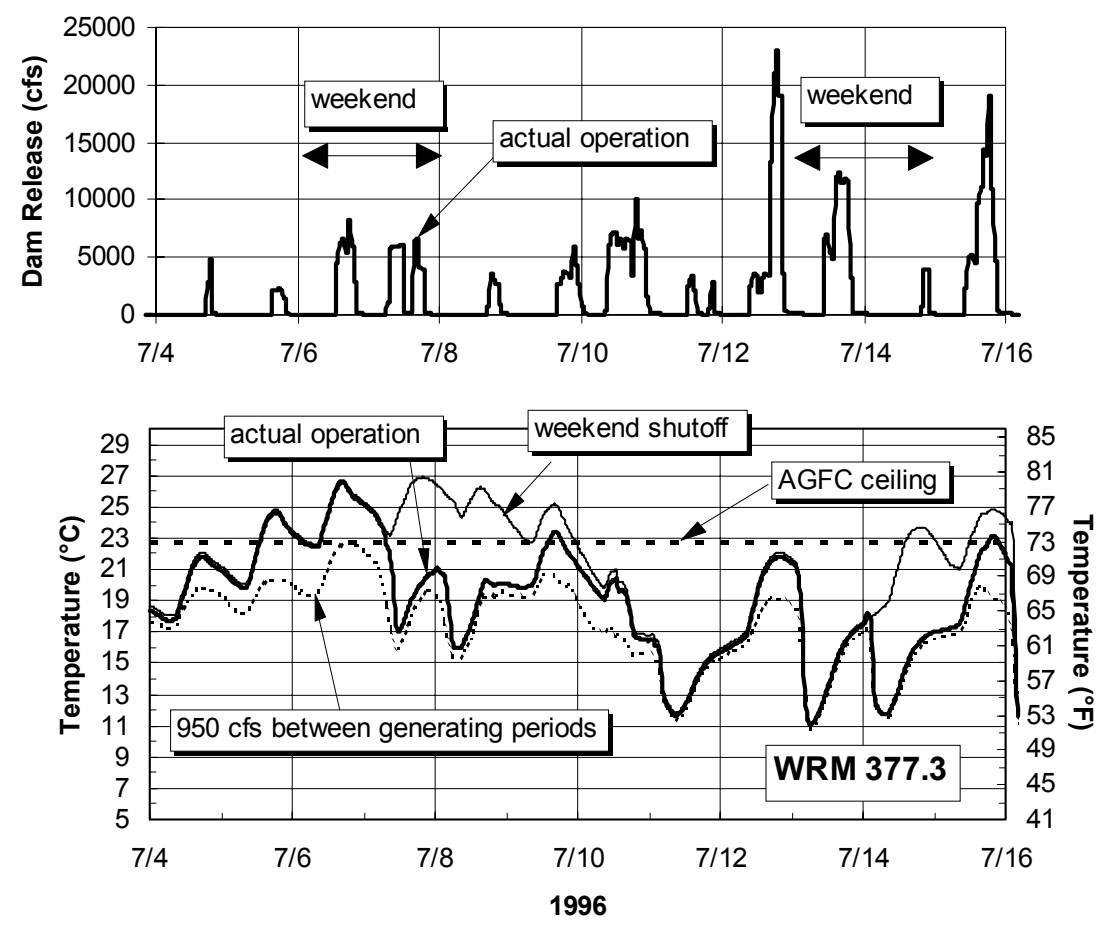

Figure 5. Effects of Dam Operations on Downstream Temperatures

day's generation, the current day's air temperature forecast, the current day's Buffalo River flow and temperature. A 2-day volume requirement with flexibility for near shutoff on one of the days would create less hydropower impact than with the 1-day volume requirement.

The suggested minimum volumes above were developed for typical summer meteorological conditions. It was possible that supplemental flow would be required under more extreme meteorology or warmer release temperature. To this end, strategically-timed blocks of generation were simulated to evaluate potential for targeted cooling in certain portions of the tailwater. A 2-hr block of generation starting at about midnight, with the remainder of the minimum daily volume on the afternoon peak, would be optimally timed for providing greatest temperature relief below the Buffalo River confluence. Any option that shifted some of the typical afternoon generation toward this optimal hour for temperature (i.e., generating earlier in the morning or later in the evening) was found to improve temperature significantly somewhere along the middle to lower end of the tailwater. Figure 6 shows an example of targeted cooling. Case 1 is 1600 cfs-days released as afternoon generation, and Case 2 is the same daily volume distributed as a 2-hour 2-turbine release from 6 to $8 \mathrm{a} . \mathrm{m}$. with the remainder as afternoon generation. Case 2 reduced maximum temperatures by 2 to $4{ }^{\circ} \mathrm{C}$ in the middle third of the tailwater. 


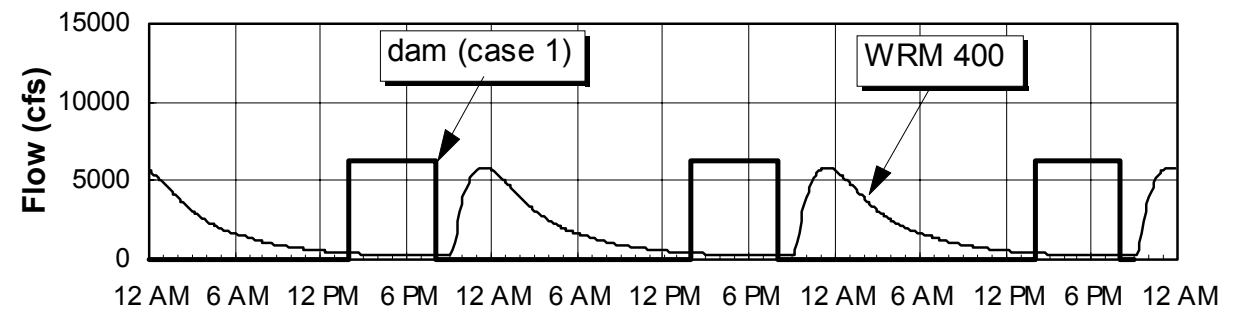

Time (hrs)
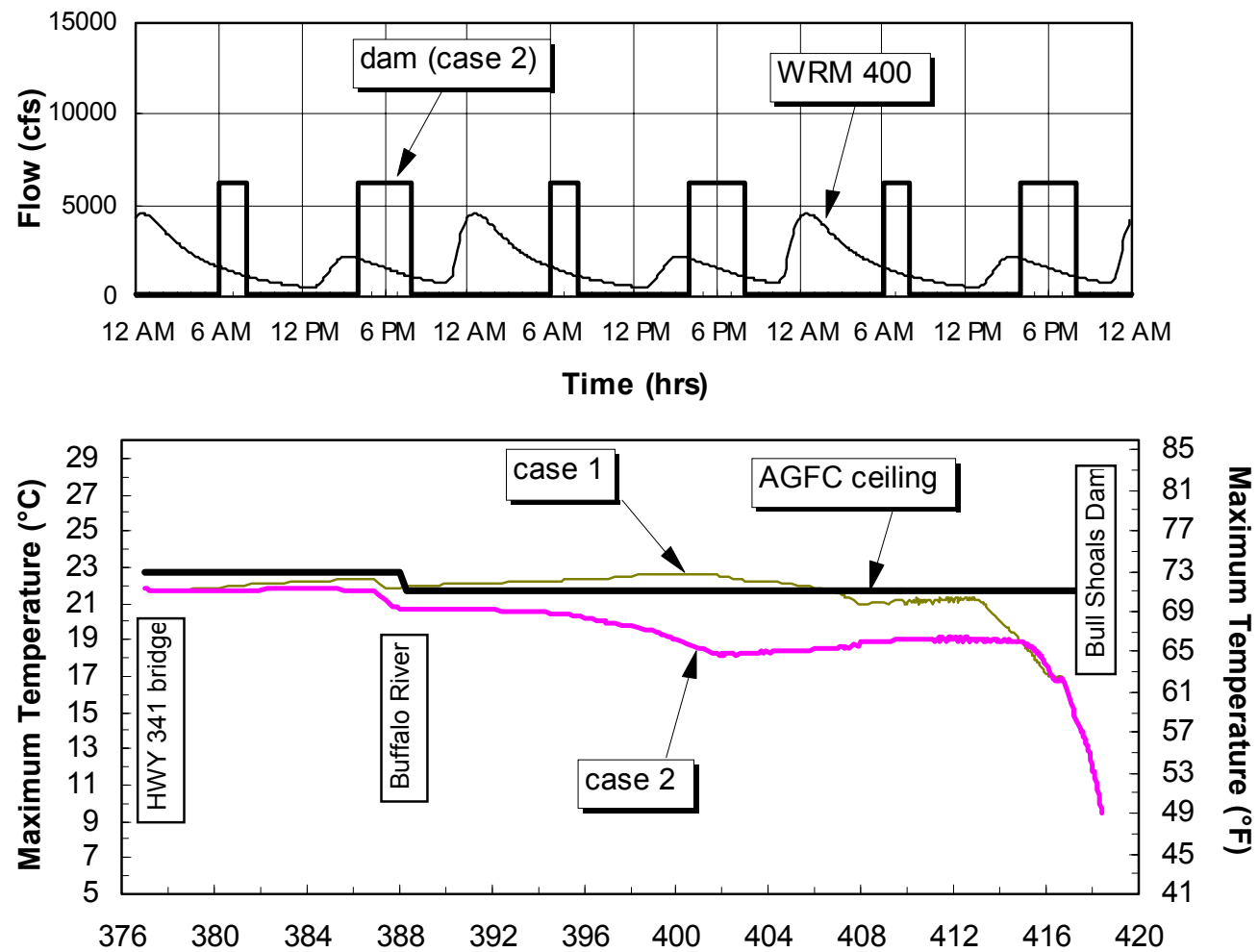

White River Mile

Figure 6. Effects of Morning Pulse on Downstream Temperature Maxima

\section{Dam Releases and Fish Growth}

Bioenergetics modeling was used to quantify fish growth responses to changes in DO and temperature below Bull Shoals and Norfork. Food availability parameters were estimated for Bulls Shoals and Norfork bioenergetics modeling based on previous model applications to Norris and South Holston tailwaters (Shiao, 1993), which are important rainbow and brown trout fisheries in the Tennessee Valley. Potential aeration systems considered for Bull Shoals and Norfork include turbine venting, forced air, oxygen diffusers in the forebay, and aerating weirs. "Throttled" systems (forebay oxygen, forced air) vary the oxygen or air supply seasonally according to need to meet a flat DO target during the low- 
DO season to avoid wasting oxygen or energy. In contrast, "passive" options (aerating weirs, turbine venting) add an increment of DO to the seasonal release pattern that depends on incoming DO and other conditions.

Model results shown in this section are for illustration of DO effects on growth. Actual selection of an aeration option includes other analysis of trade-offs, such as ability to mitigate anoxic byproducts of low DO, ability to aerate nongeneration leakage, different lengths of improved tailwater for different options, cost, and hydropower impact.

Growth simulations for a $50 \mathrm{~g}$ rainbow trout introduced the first of April are shown in Figure 7 for Bull Shoals, along with the release temperature and DO regimes (during generation) that produced this growth. These results suggest that diffuser aeration to $4 \mathrm{mg} / \mathrm{L}$ could improve growth by 2.5 to 3 times over growth without aeration. Turbine venting with DO as shown could improve growth by 3 to 3.5 times. Weir or diffuser aeration to $6 \mathrm{mg} / \mathrm{L}$ would improve growth by 5 to 7 times. For reference, current Bull Shoals operation employs turbine venting, supplemented with load reductions to increase venting whenever release DO falls below $4 \mathrm{mg} / \mathrm{L}$.

It is interesting to note in Figure 7 that the addition of aeration tends to eliminate loss of mass in the low DO season that appeared in the unaerated case. Also, Figure 7 implies that DO in excess of a target can compensate for time DO is below target. An example of this is the growth produced by the assumed DO pattern for turbine venting, which falls below $4 \mathrm{mg} / \mathrm{L}$ in late summer, compared to growth for diffuser aeration to $4 \mathrm{mg} / \mathrm{L}$. This underscores the importance of focusing on overall biological responses rather than fixed numerical criteria.

Growth sensitivity to temperature was simulated for different patterns of providing $4800 \mathrm{cfs}$-days release volume from Bull Shoals over a 3-day period. Best fish growth throughout the tailwater was produced by a case that included generation during peak hours supplemented with a 2-hour 2-turbine morning pulse (case 5 above). Less optimal cases were revealed as well. A case with $1600 \mathrm{cfs}$ constant flow each day produced sub-optimally cold upstream temperatures in the upper third of the tailwater. A case with most of the $4800 \mathrm{cfs}$-days released on the first day of the 3-day cycle (case 1 above) resulted in sub-optimally warm temperatures in all but 5 miles nearest the dam.

\section{Conclusions}

Tailwater modeling was used to clarify issues, identify alternatives, and quantify effects of release strategies to achieve environmental objectives consistent with energy production. Depth and wetted area increases in shoals areas were achievable with increased minimum flows of a few hundred cfs. Turbine pulsing showed promise for creating continuous minimum flow within short distances of Bull Shoals Dam due to the damping potential of the White River. AGFC thermal objectives could be met using a daily 1600 cfs-day release volume from Bull Shoals, and there is potential for a 2-day $3200 \mathrm{cfs}$-day volume that would provide 

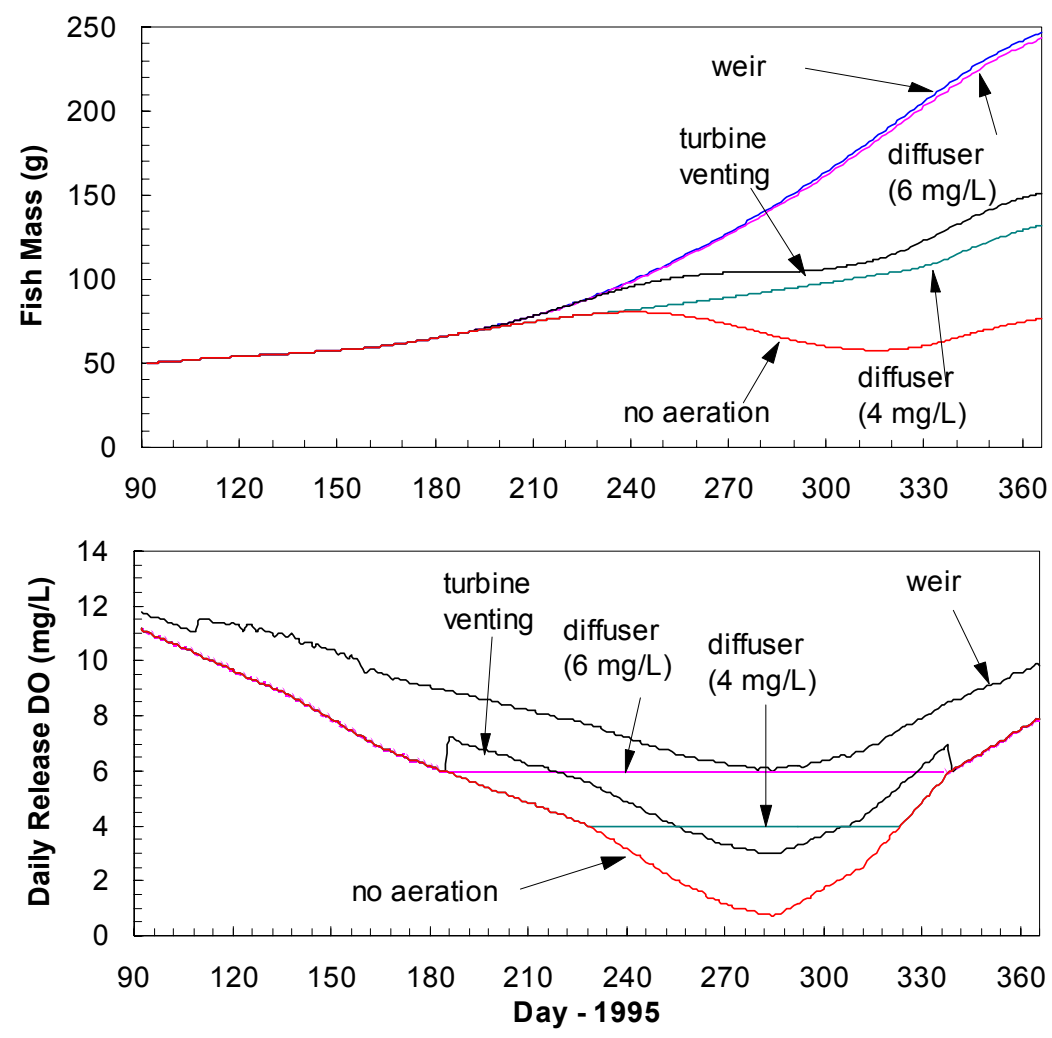

Figure 7. Effects of Aeration Options on Rainbow Trout Growth

more hydropower flexibility. Strategically timed pulses could provide supplemental cooling at mid-reach and downstream locations as meteorology dictates. Fish growth simulations showed the value of aeration at Bull Shoals and Norfork Dams. In ongoing SWPA-AGFC negotiations, benefits of minimum flows for AGFC wetted area, navigation, and temperature objectives will be weighed against hydropower costs and the reservoirs' ability to sustain these flows.

\section{References}

Hauser, Gary E., B. Hadjerioua, and M. Shiao (1998): "Model Exploration of Hydrodynamics, Water Quality, and Bioenergetics Fish Growth in Bull Shoals and Norfork Tailwaters"; WR98-1-590-174; Norris Engineering Laboratory; TVA Resource Management; Norris, Tennessee; November.

Hauser, Gary E. (1991); "User's Manual for One-Dimensional Unsteady Flow and Water Quality Modeling in River Systems With Dynamic Tributaries";

WR28-3-590-135; TVA Engineering Laboratory; Norris, Tennessee; July.

Shiao, M. C., G. Hauser, B. Yeager, T. McDonough (1993); "Development and Testing of a Fish Bioenergetics Model for Tailwaters"; WM-94-002; TVA Engineering Services and TVA Water Management Services; Norris, TN; October. 